\title{
MEDICINAL CHEMISTRY IN THE DEVELOPMENT OF SOCIETIES. BIODIVERSITY AND NATURAL PRODUCTS
}

\section{IUPAC Comission of Medicinal Chemistry*}

This document here has been elaborated by the IUPAC Medicinal Chemistry section and is backed by a large number of scientists, many of whom have had direct involvement and whose names appear at the end of the article. This work discusses the role that the discovery of new medicinal agents has in the development of societies as well as in the conservation of biodiversity in terms of the work carried out on natural products. Also included are several recommendations for countries which are presently in search of their own scientific and technological development in medicinal agents. The IUPAC Medicinal Chemistry section would appreciate the collaboration of the scientific societies in every country to aid in the diffusion of this document.

Keywords: medicinal chemistry; biodiversity; development of societies.

Modern times have seen globalization of all human endeavors accompanied by a seamless, sans frontiers, diffusion of culture, ideas and science across traditional boundaries of territories, cultures and societies. However, all societies are not at the same level of development and a significant challenge still lies in respecting and harnessing our differences to insure peace, justice and liberty for all.

For example, within the context of the life sciences a manmade medicinal agent should receive special, international attention. Any compound that can help restore lost health or prevent a disease should be made available to all countries, regardless of the continental location or the degree of societal development. The only limits that should exist are those which are organizational, linked to preparation, distribution, etc.

Presently there are countries which are the discoverers of medicinal agents and there are countries which are simply consumers. Likewise, there are countries whose legislation pertaining to intellectual property rights are quite sophisticated while there are others who do not have this type of legislation at all. Some countries are in search of development with an overabundance of natural resources and biodiversity while others have the potential for scientific and technological exploitation but lack such resources. In this wide panorama, the field of chemistry can play an important role since medicinal agents are chemical products which, in many cases, are often modified if not entirely prepared by chemical reactions. Likewise,

\footnotetext{
* Authors: A. Monge - Centro de Investigación en Farmacobiología Aplicada, Universidad de Navarra, Apdo. 177, 31080, Pamplona, España; M. Chorghade - Chorghade Enterprises, 14 Carlson Circle, Natick, MA, 01760-4205, USA.; P. W. Erhardt - Ctr. for Drug Design \& Development, Univ. Toledo, College of Pharmacy, 2801 W. Bancroft Street, Toledo, OH, 43606-3390. US; C. R. Ganellin University College London, Department of Chemistry, Christopher Ingold Laboratories, 20, Gordon Street, London, WC1H OAJ, UK.; N. Koga - Daiichi Pharmaceutical Co. Ltd., 14-10, Nihonbashi 3chome, Chuo-ku, Tokyo, 103-8234, Japan; P. Lindberg - Astra Hässle AB. S-431 83. Mölndal, Sweden; T. J. Perun - Route 4. Box 24. Hempstead. TX, 77445. USA.; J. G. Topliss - Department of Medicinal Chemistry, University of Michigan, College of Pharmacy, 428, Church Street, Ann Arbor, MI, 48109-1065, USA B. K. Trivedi - Parke-Davis Pharmaceutical Research, 2800 Plymouth Road, Ann Arbor, MI 48105, USA; C. G. Wermuth Université Louis Pasteur Strasbourg, Faculté de Pharmacie, 74, Route du Rhin, BP 24, F-67401, Illkirch Cedex, France.
}

biodiversity is attributable to chemical constituents of plants with an array of complex structures, many of which have not yet succumbed to total, practical syntheses by man. To lose biodiversity is to lose information of great potential value.

This article intends to refine and further promote ideas proposed during earlier projects of the IUPAC Medicinal Chemistry section ${ }^{1-3}$. Specifically, the authors seek to enhance the transfer of science and technology associated with drug discovery and development between developed and developing societies in the most mutually beneficial scenarios possible.

\section{INVERTING THE MODEL}

Irrespective of administrative or political considerations, companies and centers having high levels of development need to be brought together with those which lack it by means of joint projects within the broad field of chemistry and, especially, within the distinct area of biologically active compounds. Various modes of interaction can be proposed: the most often used is one wherein samples of materials from developing countries with biodiversity are extracted and transported for study in developed societies. We make a case for an inversion of this traditional model, namely that of offering technology to the countries with biodiversity so that they themselves may carry out the necessary developmental work. Chemical research conducted in the country where samples originate would enhance the country's scientific development. Competitive capacity, research methodology and the infrastructure could be the focus of negotiation and agreement. The contributions to chemical research on bioactive molecules that biodiversity-rich, developing countries may be able to then return can be ascertained on the basis of:

$>$ Strengths:

- Biological material, both of animal and vegetable origin,

with demonstrated or potential activity.

- Traditional knowledge concerning biological activities, linked to plants or animals.

$>$ Weaknesses:

- Infrastructure deficiencies which cause difficulties for conducting scientific research.

Importantly, the salient features of such programs should provide for: conservation of biodiversity; equitable intellectual property rights/duties; and, development of scientific resources/ facilities/infrastructure. 


\section{MEDICINAL CHEMISTRY AND BIODIVERSITY}

Realizing that biodiversity can be lost by man-made cataclysms such as the construction of large public works or by natural catastrophes such as fires, volcanoes etc., Medicinal Chemistry can function as a great ally by emphasizing the ecobalance between life and its surroundings, plants and microfauna and other relationships. Medicinal Chemistry also recognizes the symbiotic interaction between native communities and cultures as a foundation and wellspring for potential discoveries. These interrelationships must be nurtured and their key elements preserved. Researchers studying natural medicinal agents subscribe to this rationale. Their analysis, evaluation and effective utilization of available resources can greatly assist toward maintaining the elements of biodiversity while promoting scientific advances. Alternatively, in developing countries whose economies are based on the exploitation of agricultural and livestock resources principally geared to the production of cash crops and immediate products, there is great pressure on their natural space. Consequently, there is also great pressure toward the potential elimination of their natural flora. Thus, the relationships between biodiversity, opportunity and the structuring of various alliances become especially important relative to the immediate financial needs of a developing country. In this light, however, biodiversity and Medicinal Chemistry must find a way to collaborate and optimize opportunities based on new alliances and technology transfer that is not based-upon pure economics. Enormous benefits can accrue in the fields of education, scientific research, and innovation when an approach, other than immediate financial gain is taken.

Some examples can be illustrative. The "uña de gato," Uncaria tomentosa, DC, is a liana which has long been used by native communities of South America. However, the people from the countries where the plant grows became wary of exporting extracts for Medicinal Chemistry research because they thought they might not receive commensurate benefits. Ultimately the plant became offered on the net, in any quantity anywhere in the world by a few financially opportunistic companies. The result is that the opportunity toward incorporating technology and technological development for the countries that originally possessed the plant has been lost. Alternatively, the domestication of plants, such as the Catharanthus roseus G. Don of great interest in the production of anti-cancer alkaloids like vincristine, represents a form of conservation of biodiversity, of training in agricultural techniques of economic interest, and of the creation of a local chemical industry.

\section{MEDICINAL CHEMISTRY AND OWNERSHIP OF NATURAL RESOURCES}

Recognizing the sovereign rights that each country has over its resources ${ }^{4}$, the aim of this report is to prompt compromises between developed countries and developing countries in the area of ownership. New circumstances ${ }^{5}$ have emerged that suggest reform of the traditional system of patents essential for commercialization and diffusion of science. Presently, when a native community produces a unique cloth, it can be copied by the whole world because it is not legally protected. Alternatively, when an entity in a developed country copies and registers modifications based on the designs of a native community, absolutely no one, not even the original artists, can legally copy them ${ }^{6}$. It could be argued that the native community has the sole responsibility to register its work in order to obtain legal protection. However, such countries are typically unable to do this because of a lack of knowledge regarding these types of procedures or due to a scarcity of the means to achieve such ends. The same situation can happen with a galenic preparation of a plant that has biological activity when initially used by a traditional culture.
Establishing ownership may not be simple. It is imperative to begin by defining the discoverer ${ }^{7}$. In the discovery of medicinal agents, by traditional ways of Medicinal Chemistry, this can correspond to an individual researcher or to an entire research team. In plants with therapeutic applications originating from native communities, the question is much more complicated. Here we are speaking more of a "chain" of inventors. This can result in problems when it comes to the selection of the beneficiaries and the distribution of the benefits obtained. A matter of equal importance is the fact that certain cultures hold nature to be sacred and look askance at any attempts at its legal protection as a prelude to commercialization.

Whether the traditional use of a plant for a given pathology constitutes public property and prior art is a vexing question. The protection of knowledge, within the context of plants with biological activity, cannot be easily accomplished via patents and it becomes necessary to search for further avenues. From the standpoint of equity, answers may be able to be found during the transfer of knowledge. Consider that the number of plants which are presently used in their original form in therapeutics is quite limited. In practice it is the process of bio-directed fractionation of plant extracts that eventually permits us to find compounds which then typically also undergo further structural modification to ultimately provide preferred molecules that are more active and less toxic. Consequently, in this type of scenario a patent covering the initial plant material may not be adequate. The solution to this scenario of "plant-development" can lead to an impasse precisely for the countries in search of development, thereby possibly losing by default the possibilities for the use of their biodiversity.

Economic compensation for historical knowledge should not be lost during the overall development process because the living materials may have needed protection and conservation, sometimes throughout centuries, in order to ultimately afford the current validation of their use. This effort might be compensated for through a contract, establishing royalties that could be obtained when commercialization takes place. In line with our previous discussion, the contract might also specify in advance of commercialization and as part of a collaborative development venture, the training of persons and the acquisition of equipment and technologies as well as the more typical payment for samples. For example, compensation could be provided to the persons that provide the plant, make the extracts, and carry out biological assays, in such a way that each one can maintain his or her own interest and ultimate stake in commercialization. The country obtains benefits directly through taxation corresponding to the activities, and more importantly, through the scientific and technological upgrading of its society. The possibility of regional subsidiary or local companies playing a more important role in the transference of research and technology in such collaborative scenarios should also be seriously considered.

In countries with emerging economies, biodiversity and related activities constitute "green gold." For this reason, at times, the governments assume quick, financially-driven policies that can sometimes be contrary to eco-relationships. Thus, both parties must be prepared to adopt longer-range planning considerations into their decision-making processes. Equity and equal opportunity must be given to protect the discoveries made by any society. This principle of equity can ameliorate any misunderstanding arising out of the actions of medicinal chemists in developed countries in their relationship with their counterparts in developing countries.

\section{SUMMARIAL POINTS}

Medicinal Chemistry research on extracts from plants and other living organisms that leads to the discovery of therapeutic agents, can also be an important factor toward maintaining biodiversity. 
Relationships between societies which possess important biodiversity and developed societies which possess advanced technological processes should be based on the principles of equity. They should operate by means of collaborative contracts which acknowledge progression of scientific research in such a way that the immediate financial aspects are not considered to be of primary interest but rather only a legitimate, longer-term consequence of such partnering ${ }^{8,9}$.

$>$ Since all of humanity benefits from the discovery of new drugs, all societies should collaborate in the preservation and evaluation of the areas of great diversity from which such structures might emerge. This could be carried out through investments made by pharmaceutical companies to help preserve this type of land (e.g. of great biodiversity, of fragile environment, or where promising species prosper) and through the promotion of localized searches done in collaborative settings that can allow for both immediate development of identified actives and sustained cultivation of undefined biodiversity.

\section{ADDITIONAL RECOMMENDATIONS}

$>$ Strengthen international relationships on these types of research projects, particularly including countries at different levels of development.

$>$ Utilize university-company relationships within lessdeveloped countries.

$>$ Strengthen international relationships between scientists and the authorities responsible for research in various countries.

\section{ACKNOWLEDGMENTS}

The following persons have collaborated in this work. (May 2, 2000)

Alcudia González, Felipe. Departamento de Química Orgánica y Farmacéutica. Universidad de Sevilla, 41012 Sevilla, SPAIN (Red Iberoamericana de Investigación, Diseño y Desarrollo de Medicamentos [ RIIDDMED] - CYTED)

Aldana, Ignacio. Dpto. Química Orgánica. Facultad de Farmacia. Universidad de Navarra. C/ Irunlarrea, s/n. 31008 Pamplona. SPAIN

Benaim, Marisela. Laboratorios GIEMPI. C/ Bolivar. Urb. La Trinidad - Edif. Klinos .Apdo. Postal 87085. Caracas 1081. VENEZUELA (RIIDDMED - CYTED).

Cerecetto, Hugo. Facultad de Química y Ciencias. Universidad de la República. Montevideo. URUGUAY. (RIIDDMED - CYTED).

Compagnone, Reinaldo S. Escuela de Química. Facultad de Ciencias. Universidad Central de Venezuela. Apdo. 47102. Caracas. VENEZUELA. (RIIDDMED - CYTED).

Chiriboga P, Ximena. Universidad Central del Ecuador. Facultad de Ciencias químicas. Departamento de Fitoquimica y Productos Naturales. Salazar Gómez No N32 - 01 y Martínez .Mera. Quito. ECUADOR. (RIIDDMED - CYTED).

Domínguez, José N. Universidad Central de Venezuela. Facultad de Farmacia. Apdo. 40109.Nva. Granada. Caracas. VENEZUELA. (RIIDDMED - CYTED).

Farré, Antonio J. Lab. Dr. Esteve. M.D.D.Montserrat 221. 08041 Barcelona. SPAIN. (RIIDDMED - CYTED).

Fernández Braña, Miguel. Universidad San Pablo Ceu.
Facultad de Ciencias Experimentales. Urb. Montepríncipe. Ctra. Boadilla del Monte, 5,300. 28668 Madrid. SPAIN. (RIIDDMED - CYTED).

Ferrándiz García, Francisco. Vocal Asesor de Rel. Internacionales. OCYT. C/ José Abascal, 4. 28003 Madrid. SPAIN

Ferro, Esteban. Facultad de Ciencias Químicas. Universidad Nacional de Asunción. Fac. de Ciencias Químicas. Dirección de Investigación. Departamento de Fitoquímica. Campus Universitario. San Lorenzo. PARAGUAY.

Fischer, Janos. Richter Co., Ltd. P.O. Box 27. H- 1475 Budapest, 10. HUNGARY

Gattuso, Martha. Universidad Nacional de Rosario. Fac. Ciencias Bioquímicas y Farmacéuticas. Biología Vegetal. Suipacha, 531. 2000 Rosario, ARGENTINA

Gattuso, Susana. Universidad Nacional de Rosario. Fac. Ciencias Bioquímicas y Farmacéuticas. Biología Vegetal. Suipacha, 531. 2000 Rosario, ARGENTINA

Guccione Salvatore. University of Catania (Italy), Dipartimento di Scienze Farmaceutiche, viale A. Doria 6, Ed. 12 Città Universitaria, I-95125 Catania. ITALY

Huenchuñir Gómez, Patricio. Facultad de Medicina, Universidad de los Andes. San Carlos de Apoquindo 2200. 6782468. Las Condes. Santiago. CHILE. (RIIDDMED - CYTED).

Kobayashi, Toshi. PhRMA-Japan. SB Building. 6 Sanbancho. Chiyodaku. Tokyo. 102-0075. JAPAN

Martín, Yolanda. Dpto. Química. Universidad Europea de Madrid. Villaviciosa de Odón. 28670 Madrid. SPAIN. (RIIDDMED - CYTED).

Ochoa de Ocáriz, Carmen. Instituto de Química Médica. Juan de la Cierva, 3. 28006-Madrid. SPAIN. (RIIDDMED - CYTED).

Sener, Bilge. Director. Department of Pharmacognosy. Faculty of Pharmacy. Gazi University. P.K. 143. 06572 Mattope. Ankara. TURKEY.

Vega Noverola, Salvador. Instituto de Química Médica. Juan de la Cierva, 3. 28006-Madrid. SPAIN. (RIIDDMED - CYTED).

Zacchino, Susana. Universidad Nacional de Rosario. Fac. Ciencias Bioquímicas y Farmacéuticas. Farmacognosia. Suipacha, 531. 2000 Rosario, ARGENTINA. (RIIDDMED - CYTED).

\section{REFERENCES}

1. Andrews, P. R.; Borris, R.; Dagne, E.; Gupta, M.; Mistcher, L. A.; Monge, A.; de Souza, N. J. and Topliss, J. G.; Chem. Int. 1997, 19, 77. (Summary of Technical Report).

2. Andrews, P. R.; Borris, R.; Dagne, E.; Gupta, M.; Mistcher, L. A.; Monge, A.; de Souza, N. J. and Topliss, J. G.; Chem. Int. 1997, 19, 77. (Summary of Technical Report)

3. Monge, A.; Ganellin, R.; Ide, J.; Koga, N.; Mitscher, L.; Muller, C.; Perun, T. J.; Topliss J. G. and Wermuth, C. G.; Chem. Int. 1999, 21, 65.

4. The Phuket Declaration. Chem. Int. 1998, 20, 139.

5. Borman, S; $C \& E N$ 1999, 77,49

6. Quéan, P.; Fuentes (UNESCO) 1999, 117, 4.

7. R. Pidgeon, R.; Chem. Br. 1999, 35, 25.

8. Nettleton Jr., D. E.; (DN\&P). Drugs, News and Perspectives 1995, 8, 250.

9. Rodríguez, C. M.; "Legal Issues: Contracts, Intellectual property rights and other property rights", pp. 183-190, in "Biodiversity, Biotechnology and Sustainable Development, in Health and Agriculture: Emerging Connections". Edt.: Organización Panamericana de la Salud, (OPS) Director de la publicación: George A.O. Alleyne; Washington 1996. 